\title{
Construction of Various Regular Computational Grids for Addressing the Tasks of Fluid Location of the Atmosphere
}

\author{
E.S. Nagovitsyna ${ }^{1,2, a)}$, V.A. Poddubny ${ }^{1, b)}$, D.A. Vilinsky ${ }^{1)}$ \\ ${ }^{1}$ Institute of Industrial Ecology of the Ural Branch of the Russian Academy of Sciences, S. Kovalevskaya 20, \\ Ekaterinburg, Russia, 620990 \\ ${ }^{2}$ Ural Federal University, Mira 19, Ekaterinburg, Russia, 620002

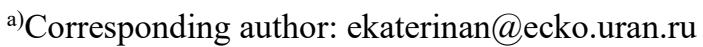 \\ b)Vassily.Poddubny@gmail.com
}

\begin{abstract}
The method of Fluid Location of the Atmosphere (FLA) [1-3] is the development of back trajectory statistics methods (BTS) [4-6], which allow to evaluate spatial structure of atmospheric contaminants, which are measured in a finite number of monitoring sites. In any variant of the BTS method, a fixed (Euler) grid is used to divide the investigated region into a set of fixed volume spatial cells. The common example of a fixed grid is a latitude - longitude grid. However, a latitude-longitude grid becomes inconvenient for solving some tasks, such as reconstructing of the concentration fields in the Polar Regions. The aim of this work is to build an alternative grid for the tasks of the FLA method, as well as to compare and analyze simulation results obtained on the basis of various grids.
\end{abstract}

Keywords: atmospheric aerosol, simulation, back trajectory statistics, triangular grid.

\section{FEATURES OF TRIANGULAR GRIDS FOR THE PURPOSE OF THE FLA}

The latitude - longitude grid has a number of indisputable advantages, the main of which are the ease of construction and simple mathematic calculations. But there are significant shortcomings, the most critical of which is the change of the areas of calculation cells in the meridional direction, and, as a result, the inability to use this grid near the poles. The triangular grid lacks this disadvantage.

As compared to the latitude - longitude grid, building the triangular grid is a more time-consuming process. In this paper, we use the triangular grid constructed on the basis of the following rules. The initial triangles are the basic spherical ones whose vertices coincide with the vertices of an icosahedron inscribed in a sphere whose radius is equal to the average radius of the Earth $(6371 \mathrm{~km})$ [7]. The construction of the triangular grid is performed by bisection of the triangle sides, as a result of which four new triangles are formed. This manipulation is repeated until the resolution of the grid satisfies a certain condition. The fifth generation triangular grid (obtained by five subsequent divisions of the basic triangle) constructed according to these rules and the distribution of the cell areas are shown in Figure 1. All cell areas are normalized to the maximum area that is characteristic of the central cell of the basic triangle.

Among the disadvantages of the triangular grid the following can be emphasized:

a) Constructing the grid with a given cell size is impossible. The length of the cell side is the result of dividing the sides of the original triangle by an even integer and it cannot be set arbitrarily.

b) The algorithm for estimating the average effective concentration fields by the FLA method becomes more complicated. For example, it complicates the tasks of determining the cell to which a particular point belongs and of the subsequent averaging of concentrations over cells.

The main advantage of the triangular grid is the small distortion of the shapes and areas of the computational cells around the globe. In the center of the base spherical triangle the grid will be close to regular. The strongest variations of areas will be near the corners of the basic triangle.

International Conference of Numerical Analysis and Applied Mathematics ICNAAM 2019

AIP Conf. Proc. 2293, 120013-1-120013-4; https://doi.org/10.1063/5.0026693

Published by AIP Publishing. 978-0-7354-4025-8/\$30.00 

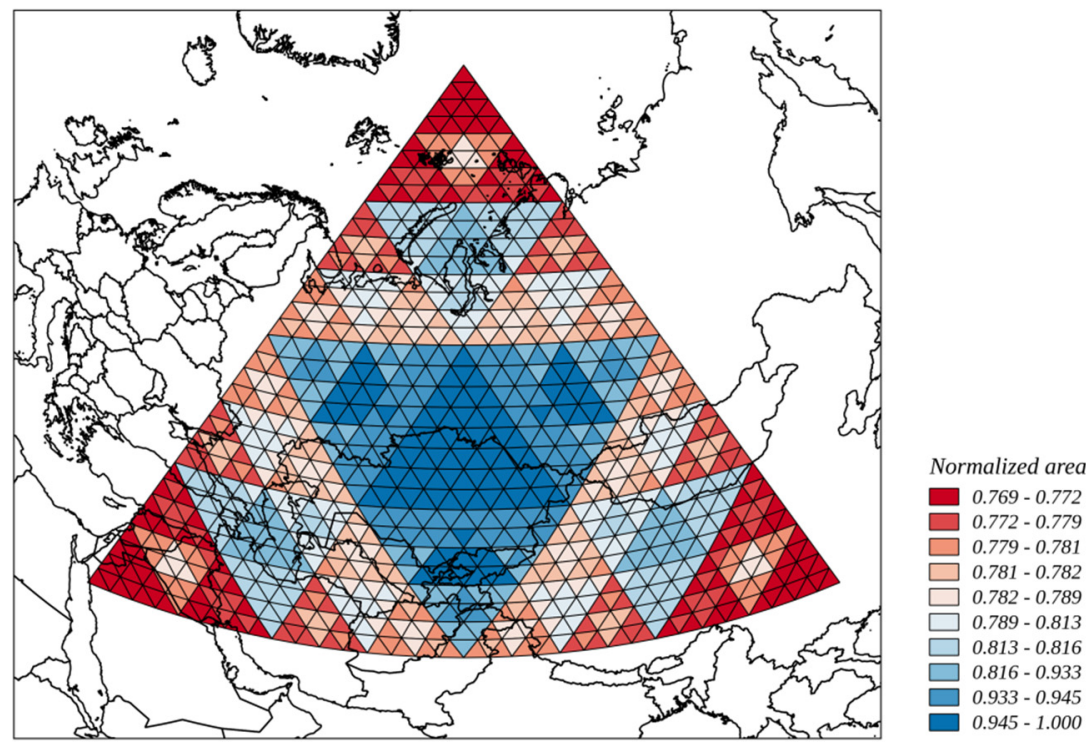

FIGURE 1. The distribution of the normalized cell areas of the fifth generation triangular grid.

\section{COMPARISON OF SIMULATION RESULTS OBTANED ON THE BASIS OF THE LATITUDE - LONGITUDE AND THE TRIANGULAR GRIDS}

For the comparison of the grids, calculations by the FLA method were made based on the results of photometric measurements of 2016. As the input information, volume concentrations of submicron aerosol in the atmospheric column were used, which were obtained by numerical integration of the aerosol size distribution of the particle volume at the AERONET [8] monitoring station located in the Middle Urals. For the convenience of analysis and comparison of the results obtained, the calculated fields are normalized to the average value of the volume concentration of the submicron aerosol $\left(0.029 \mu \mathrm{m}^{3} / \mu \mathrm{m}^{2}\right)$.

The four days duration back trajectories of the air flows [9], calculated by the HYSPLIT software package [1013] for $500 \mathrm{~m}$ altitude above ground level, were used as information on the dynamics of the atmosphere. In this work the use of back trajectories on the single altitude means that the results of simulation discussed below represent the quasi-two-dimensional fields of the submicron aerosol concentration distribution in space, i.e. they are an estimate of real three-dimensional fields.

The average effective fields of the normalized submicron aerosol volume concentration retrieved with the FLA method on the basis of the triangular and the latitude - longitude $\left(1^{\circ} \times 1^{\circ}\right.$ resolution) grids are shown in the Figures 2 and 3, respectively. The star signs mark the AERONET network monitoring site in the Middle Urals. High average aerosol concentrations are observed to the east of the monitoring site. The reason for that is strong wildfires in the Eastern Siberia in the summer 2016. In addition, the boundaries of states are shown, as well as the coastline of continents and islands.

The basic statistical characteristics of average effective fields of normalized submicron aerosol concentrations calculated on the basis of latitude - longitude and triangular grids and shown in the Figures 2 and 3 are described in the Table 1. Since the size of samples is almost the same ( 800 cells for the latitude - longitude grid and 802 for the triangular grid), obtained statistical values may be comparable. In the entire calculated region the absolute difference between the minimum values of the normalized average submicron aerosol concentrations was 0.09 units, with a relative difference of $64 \%$. The difference in maximum values is 0.8 units, and the relative difference is $19 \%$. Good comparability of statistical parameters, such as average value, standard deviation, maximum and minimum values, indicates the quantitative similarity of the obtained results. It should be noted that the average concentration over the entire calculated region is close to the average value of submicron aerosol volume concentrations measured at the monitoring site. 


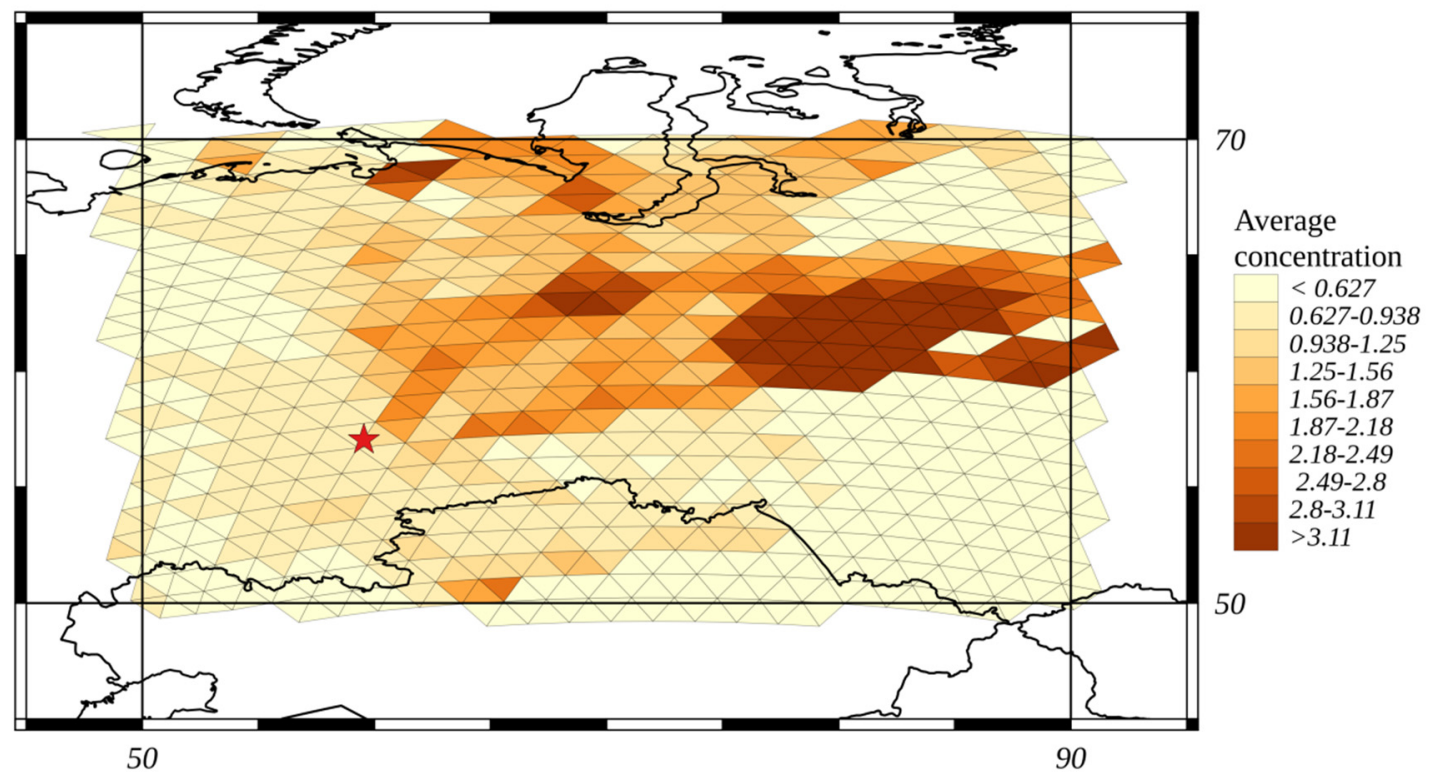

FIGURE 2. The result of calculating the average effective field of normalized concentrations of submicron aerosol by the FLA method on a triangular grid.

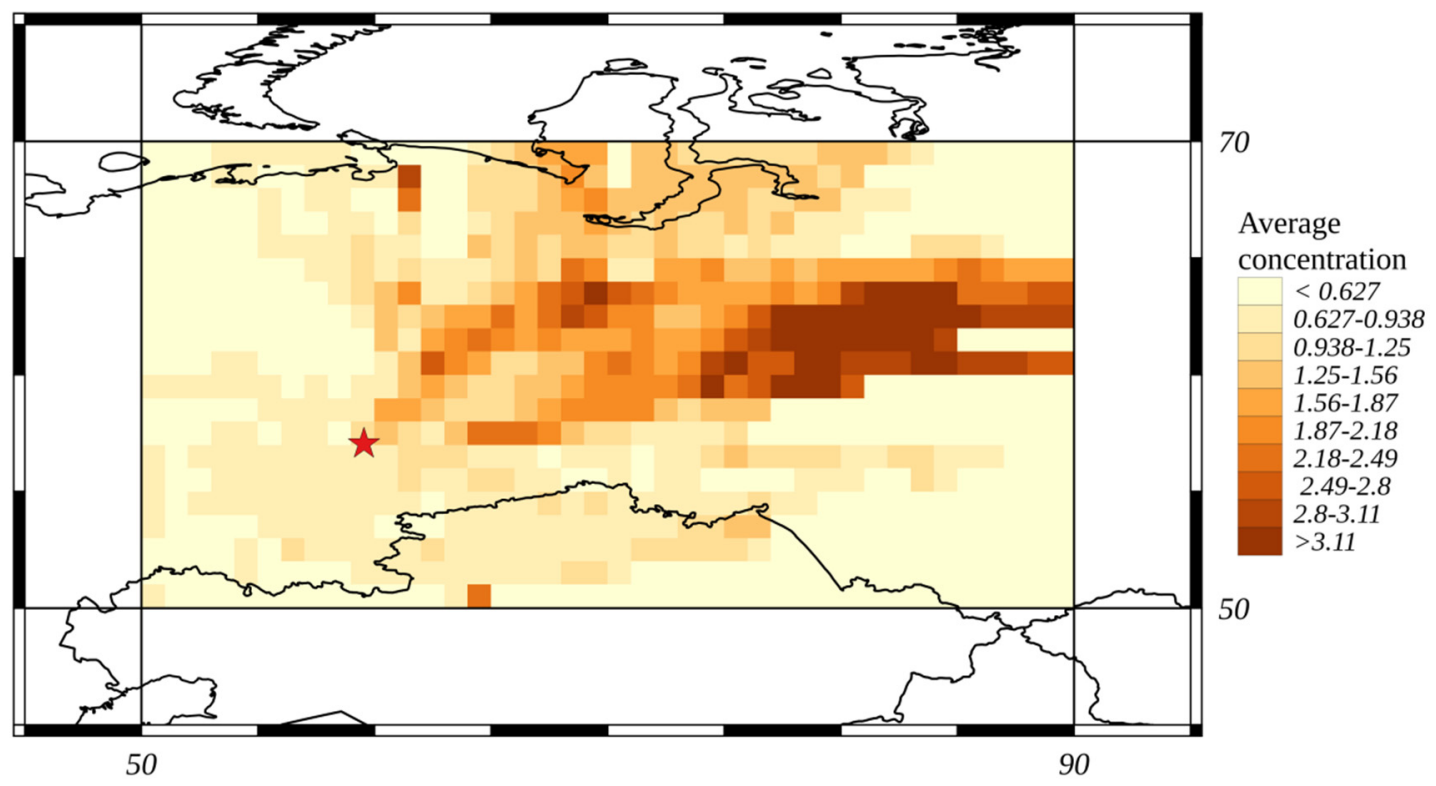

FIGURE 3. The result of calculating the average effective field of normalized concentrations of submicron aerosol by the FLA method on a latitude - longitude grid. 
TABLE 1. The basic statistical characteristics of average effective fields of normalized submicron aerosol concentrations.

\begin{tabular}{ccc}
\hline & Longitude-latitude grid & Triangular grid \\
\hline Number of grid cells & $\mathbf{8 0 0}$ & $\mathbf{8 0 2}$ \\
\hline & Normalized submicron aerosol volume concentrations \\
\hline Minimum & 0.229 & 0.140 \\
1 quintile & 0.354 & 0.348 \\
Median value & 0.748 & 0.781 \\
Mean & 1.030 & 1.061 \\
3 quintile & 1.318 & 1.400 \\
Maximum & 4.912 & 4.119 \\
Standard deviation & 0.840 & 0.878 \\
\hline & Cell areas of computational grid, km \\
\hline Minimum & 4329.83 & 5853.17 \\
Maximum & 7864.04 & 7514.30 \\
\hline
\end{tabular}

\section{ACKNOWLEDGMENTS}

The reported study was funded by RFBR according to the research project № 18-31-00170.

\section{REFERENCES}

[1] V.A. Poddubny and E.S. Nagovitsyna, "Retrieval of spatial field of atmospheric aerosol concentration according to data from local measurements: a modification of the method of back trajectory statistics", Izv. RAS, Physics of the atmosphere and ocean 49, 439-446 (2013).

[2] V.A. Poddubny and E.S. Dubinkina, "The problem of fluid location of the atmosphere for the estimation of pollution fields and retrieval of source", Optics of the atmosphere and the ocean (In Russian) 30, 862-870 (2017).

[3] E.S. Dubinkina and V.A. Poddubny, "Numerical implementation for the fluid location of atmosphere method", Mathematical simulation (In Russian) 30, 33-47 (2018).

[4] L.L. Ashbaugh, "A statistical trajectory technique for determining air pollution source regions", J. Air Pollut. Control. Ass. 33, 1096-1098 (1983).

[5] P. Seibert, H. Kromp-Kolb, U. Baltensperger, and et al., "Trajectory analysis of aerosol measurements at high alpine sites," Transport and Transformation of Pollutants in the Troposphere, 689-693 (1994).

[6] A. Stohl, "Trajectory statistics - a new method to establish source-reseptor relationships of air pollutants and its application to the transport of particulate sulfate in Europe," Atmos. Environ. 30(4), 579-587 (1996).

[7] M.Z. Jacobson, Fundamentals of Atmospheric Modeling, $2^{\text {nd }}$ Ed (Cambridge University Press, 2005), 813 p.

[8] B.N. Holben, T.F. Eck, I. Slutsker, and et al., "Aeronet a federated instrument network and data archive for aerosol characterization", Remote Sens. Environ. 66., 1-16 (1998).

[9] A. Stohl, "Computation, accuracy and applications of trajectories - a review and bibliography," Atmos. Environ. 32(6), 947-966 (1998).

[10] R.R. Draxler and G.D. Hess, "An overview of the hysplit-4 modeling system for trajectories, dispersion and deposition", Australian Meteorological Magazine, 47, 295-308 (1998).

[11] V.A. Poddubny, E.S. Dubinkina, J.I. Markelov, A.G. Buevich, K.L. Antonov, E.V. Omelkova, I.L. Manzhurov, and A.N. Medvedev, "Recovery of average effective methane concentration field in the region of Kara and Barents Seas using a passive location of the atmosphere by wind", AIP Conference Proceedings 2040, 050020 (2018); https://doi.org/10.1063/1.5079118.

[12] Konstantin L. Antonov, Vassily A. Poddubny, Yury I. Markelov, Alexander G. Buevich, and Alexander N. Medvedev, "Dynamics of surface carbon dioxide and methane concentrations on the Arctic Belyy Island in 2015-2017 summertime", Proc. SPIE 10833, 24th International Symposium on Atmospheric and Ocean Optics: Atmospheric Physics, 108336H (13 December 2018).

[13] V.A. Poddubny, E.S. Dubinkina, J.I. Markelov, A.G. Buevich, K.L. Antonov, E.V. Omelkova, I.L. Manzhurov and A.N. Medvedev, "The Results of the Retrieval of Average Atmospheric Methane Fields from Summer Ground-Based Measurements on Bely Island in 2016 and 2017", AIP Conference Proceedings 2116, 200024 (2019); https://doi.org/10.1063/1.5114205. 